\title{
Comparison of efficacy between trimetazidine and cilostazol in the treatment of arteriosclerosis obliterans in lower extremity
}

\author{
MIN HU*, DILE WANG* and TAO HE \\ Department of Vascular Surgery, The Central Hospital of Wuhan, Tongji Medical College, \\ Huazhong University of Science and Technology, Wuhan, Hubei 430014, P.R. China
}

Received November 14, 2018; Accepted March 19, 2019

DOI: $10.3892 / \mathrm{etm} .2019 .7472$

\begin{abstract}
This study compared the efficacy and long-term survival rate of trimetazidine and cilostazol in the treatment of lower extremity arteriosclerosis obliterans (ASO). A retrospectively analysis on the medical records of 206 patients with ASO who were admitted to The Central Hospital of Wuhan from January 2011 to May 2013 was performed, including 94 patients treated with trimetazidine (group A) and 112 patients treated with cilostazol (group B). On the basis of the same basic treatment, both groups were applied with these two drugs after two courses of treatments. Then the efficacy of clinical treatment, dorsal artery blood flow, anterior femoral artery, posterior tibial artery blood flow, brachial artery index, toe-brachial index, painless walking distance, maximum walking distance, adverse reactions, 5 -year survival rates were compared. The total effective rate of clinical efficacy in group B was higher than group A $(\mathrm{P}<0.05)$. After the first course of treatment, the above indicators increased in both groups $(\mathrm{P}<0.05)$. After the end of the second course of treatment, the above-mentioned index values in both groups were significantly increased $(\mathrm{P}<0.05)$. The improvement of the above indicators in group $B$ were better than the trimetazidine group in both the first and second treatment courses $(\mathrm{P}<0.05)$. In group $\mathrm{A}$, there were 15 cases of patients with lethargy and hypodynamia and 9 cases of dizziness and headache. There were significant differences between the 7th and 3rd cases of patients when compared to group $\mathrm{B}(\mathrm{P}<0.05)$. The 5-year survival rate of group A was lower than group $\mathrm{B}(\mathrm{P}<0.05)$. The clinical efficacy of cliostazol in the treatment of ASO had a good effect,
\end{abstract}

Correspondence to: Dr Tao He, Department of Vascular Surgery, The Central Hospital of Wuhan, Tongji Medical College, Huazhong University of Science and Technology, 26 Shengli Street, Jiangan, Wuhan, Hubei 430014, P.R. China

E-mail:tkg8ve@163.com; taohewuhan@sina.com

${ }^{*}$ Contributed equally

Key words: trimetazidine, cilostazol, lower extremity arteriosclerosis obliterans, efficacy and there was only a few adverse reactions and the long-term survival rate was high. It is worthy of being promoted in clinical practice.

\section{Introduction}

Lower extremity arteriosclerosis obliterans (ASO) is an important manifestation of atherosclerosis. The lower extremities are common for a series of physical disorders caused by the leg arterial blood supply disorders, and atherosclerosis occur in the peripheral arteries (1). The main symptoms in the early stage are intermittent claudication and the distal arterial pulsation gradually weakens or even disappears. As the symptoms worsen in the later stages, patients may experience rest pain, and skin temperature decreases significantly with the development of diseases, cyanosis, toe ulcers and gangrene. Severe cases can even lead to amputation and affect patients' quality of life. With the continuous improvement of living standards the social population is developing an aging trend. ASO is more common in the lower limbs due to diseases, lower extremity arterial blood pressure and vulnerable intima, which has become the main cause of limb loss in adulthood worldwide (2).

Common methods for medical treatment of ASO include antihypertensive, lipid-lowering and anti-platelet aggregation. However, these treatments can only delay the progression of the disease (3). Trimetazidine is a clinically used drug for the treatment of coronary insufficiency, and is a 3-KAT inhibitor and an anti-ischemic drug (4), which can inhibit tissue damage caused by oxidation and tissue fibrosis (5-7) and reduce fat metabolism caused by intracellular acidosis and anaerobic metabolism of ischemic cells (8). Cilostazol is a drug that can effectively inhibit the aggregation of platelets, inhibit the activity of phosphodiesterase III and blocking the degradation and transformation of adenylate cyclase, and can increase the content of adenylate cyclase in platelets and vascular smooth muscle cells, endothelial cells, cardiomyocytes and adipocytes and exerts anti-platelet aggregation and vasodilatation of cilostazol $(9,10)$. Cilostazol can inhibit platelet aggregation, the proliferation of vascular smooth muscle cells and protects endothelial cells during inflammation (11), and has anti-thrombotic effect, which is mainly used for the treatment of local diseases such as chronic arterial occlusive ulcer, pain and cold sensation. 
Currently, there are only a few studies on the difference between the efficacy and long-term survival rate of trimetazidine and cilostazol in the treatment of ASO patients. This study compared the therapeutic effects of trimetazidine and cilostazol in the treatment of patients with ASO to identify a better-acting drug for the treatment of this disease, and intended to provide a basis for the treatment of ASO.

\section{Materials and methods}

General information. A retrospective analysis of the medical records of 206 ASO patients from January 2011 to May 2013 in The Central Hospital of Wuhan (Wuhan, China) was performed. The Fontaine stage cases were: 40 cases $(19.42 \%)$ in stage I, 58 cases $(28.16 \%)$ in stage II, 72 cases in stage III (34.95\%) and 36 cases $(17.48 \%)$ in stage IV. According to the clinical treatment, 94 patients were treated with trimetazidine (group A) and 112 patients with cilostazol (group B). There were 62 males and 32 females in group A, with an age range of 40-75 years, with an average of $(63.5 \pm 18.8)$ years, 22 with diabetes, 28 with hypertension and 21 with hyperlipidemia. There were 77 males and 35 females in group B, with an age range of 40-83 years, with an average of $(69.5 \pm 17.3)$ years, 32 with diabetes, 22 with hypertension, and 33 with hyperlipidemia.

\section{Inclusion and exclusion criteria}

Inclusion criteria. The primary inclusion criterion was complying with the diagnostic criteria for ASO patients in the guidelines for the Treatment of Lower Extremity Arteriosclerosis Obliterans. Other criteria were intermittent ischemic symptoms such as lameness, numbness, pain and fatigue, and no drugs taken recently to treat ASO.

Exclusion criteria. Patients with clinical manifestations but not diagnosed with ASO after relevant examinations; patients with severe liver and kidney related disease, malignant tumors, active infections, chronic respiratory diseases and hematopoietic dysfunction; patients who had a history of myocardial infarction; pregnant; patients with contraindications to anticoagulant thrombolysis and with a history of mental illness or family mental illness and bleeding (Hemophilia, capillary fragility, intracranial hemorrhage, gastrointestinal bleeding, urinary tract bleeding, hemoptysis and vitreous hemorrhage) were excluded from the present study.

The study was approved by Ethics Committee of The Central Hospital of Wuhan, and patients or their families signed a full informed consent form.

Drugs. The drug used in the experiment was: trimetazidine, produced by Servier Tianjin Pharmaceutical Co., Ltd. (Tianjin, China), specification $20 \mathrm{mg}$ x 30 tablets. Product batch number was: national medicine quasi-word H20055465; cilostazol, Zhejiang Daxie Pharmaceutical Co., Ltd. (Zhejian, China). Specification was: $50 \mathrm{mg}$ x 12 tablets, national medicine quasi-word H10960014; Alprostadil injection, produced by Xi'an Libang Pharmaceutical Co., Ltd. (Shaanxi, China); Specifications $2 \mathrm{ml}$ : $10 \mu \mathrm{g}$ x $5 \mathrm{pcs} / \mathrm{box}$, national medicine quasi-word H20103100.

Method. To control the blood pressure, blood sugar, and diet (low-salt, low-fat diet) in both groups of patients alprostadil was used to inhibit platelet aggregation. In addition, plaque was stabilized against infection, informing patients to keep warm, protecting the lower limbs from trauma, avoiding causing skin surface rupture, pus discharge and guided lower limb exercises conducted by doctors in the rehabilitation department, and promoting basic treatment such as lower limb circulation. Group A was given trimetazidine, orally, $30 \mathrm{mg} / \mathrm{time}$, 3 times/day and group B was given cilostazol, orally, $100 \mathrm{mg}$ twice daily. Each course of treatment was two weeks and both groups received two courses of treatment.

Observation indexes. We observed and compared the clinical therapeutic effect, painless walking distance (PFWD), pedis artery blood flow, anterior femoral artery, posterior tibial artery blood flow, brachial artery index (pedis artery systolic pressure/brachial artery systolic pressure, ABI), toe-brachial index (the ratio of pressure between toe artery pressure and limb artery, TBI), maximum walking distance, 5-year survival rate and other adverse reactions between the groups. Efficacy evaluation criteria were: Fully recovered: disease symptoms disappeared and regaining health; Significant effect: no symptoms of numbness and coldness in the lower extremities, intermittent claudication and disappearance of resting pain; Effective: The clinical symptoms are changed from phase I to phase II as per Fontaine staging, and the intermittent claudication distance was extended to $>500 \mathrm{~m}$; Invalid: There were no improvements in the items that were required to be observed in the experiment. Total efficiency was calculated as: (healing + markedly effective) / number of patients.

Statistical analysis. Statistical analysis was performed on the research data using SPSS 17.0 (Tianjin Soft Network Technology Co., Ltd., Tianjin, China) statistical software. The measurement data were expressed as the mean standard (mean $\pm \mathrm{SD}$ ) using the t-test and Chi-squrare test. The three time-points before and after the treatment in the group were compared using repeated measures of variance analysis and the LSD post hoc test. The data counting was expressed as a rate (\%) by using Chi-square test. Survival rates were calculated by using the Kaplan-Meier method and were compared by using the log-rank test. $\mathrm{P}<0.05$ indicated that the difference was statistically significant.

\section{Results}

Comparison of basic information between the groups. There was no significant difference in sex, age, ethnicity, height, weight, smoking, blood pressure, pathogenesis time, Fontaine stages or body mass index (BMI) between the groups $(\mathrm{P}>0.05)$ (Table I).

Comparison of efficacy between the groups of patients. In group A, there were 8 cases of fully recovered patients $(8.51 \%)$, 25 cases of significant effective patients $(26.60 \%), 41$ cases of effective patients (42.62\%), 20 non-effective cases $(21.28 \%)$ and a total of 74 effective cases $(78.72 \%)$. In group B, there were 15 cases of fully recovered patients (13.39\%), 45 cases of significantly effective patients $(40.18 \%), 41$ cases of effective patients $(36.61 \%), 11$ non-effective cases $(9.82 \%)$ and a total of 101 cases were effective $(90.18 \%)$. There was no 
Table I. Basic information between the groups of ASO patients [n (\%)]/mean \pm SD.

\begin{tabular}{|c|c|c|c|c|}
\hline Basic information & Group A (n=94) & Group B $(n=112)$ & t/Chi-square test & P-value \\
\hline Age (years) & & & 0.099 & 0.753 \\
\hline$\geq 55$ & $73(77.66)$ & 89 (79.46) & & \\
\hline$<55$ & $21(22.34)$ & $23(20.54)$ & & \\
\hline Sex & & & 0.182 & 0.670 \\
\hline Male & $62(65.96)$ & $77(68.75)$ & & \\
\hline Female & $32(34.04)$ & $35(31.25)$ & & \\
\hline Ethnicity & & & 0.004 & 0.953 \\
\hline Han & $85(90.43)$ & $101(90.18)$ & & \\
\hline Others & $9 \quad(9.57)$ & $11(9.82)$ & & \\
\hline Height (cm) & & & 0.062 & 0.803 \\
\hline$<165$ & $58(61.70)$ & $71(63.39)$ & & \\
\hline$\geq 165$ & $36(38.30)$ & $41(36.61)$ & & \\
\hline Weight (kg) & & & 0.129 & 0.719 \\
\hline$<50$ & $59(62.77)$ & $73(65.18)$ & & \\
\hline$\geq 50$ & $35(37.23)$ & $39(34.82)$ & & \\
\hline Smoking history (years) & & & 0.088 & 0.957 \\
\hline$<5$ & $29(30.85)$ & $36(32.14)$ & & \\
\hline$\geq 5$ & $33(35.11)$ & $40(35.71)$ & & \\
\hline None & $32(34.04)$ & $36(32.14)$ & & \\
\hline \multicolumn{5}{|l|}{ Blood pressure (mmHg) } \\
\hline Systolic pressure & $145.48 \pm 20.21$ & $141.35 \pm 19.92$ & 1.472 & 0.143 \\
\hline Diastolic pressure & $98.82 \pm 15.55$ & $96.76 \pm 16.35$ & 0.921 & 0.358 \\
\hline Pathogenesis time (months) & & & 0.077 & 0.781 \\
\hline$<12$ & $31(32.98)$ & $39(34.82)$ & & \\
\hline$>12$ & $63(67.02)$ & $73(65.18)$ & & \\
\hline Fontaine stages & & & 1.113 & 0.774 \\
\hline Stage I & $18(19.15)$ & $22(19.64)$ & & \\
\hline Stage II & $29(30.85)$ & $29(25.89)$ & & \\
\hline Stage III & $33(35.11)$ & $39(34.82)$ & & \\
\hline Stage IV & $14(14.89)$ & $22(19.64)$ & & \\
\hline BMI & $25.82 \pm 7.43$ & $24.48 \pm 10.11$ & 1.066 & 0.288 \\
\hline
\end{tabular}

Table II. Comparison of the efficacy of ASO patients between both groups [n (\%)].

\begin{tabular}{lccccrr}
\hline Item & $\mathrm{n}$ & Fully recovered & Significant effective & Effective & Non-effective & Total effective \\
\hline Group A & 94 & $8(8.51)$ & $25(26.60)$ & $41(43.62)$ & $20(21.28)$ & $74(78.72)$ \\
Group B & 112 & $15(13.39)$ & $45(40.18)$ & $41(36.61)$ & $11(9.82)$ & $101(90.18)$ \\
$\chi^{2}$ & - & 1.228 & 4.203 & 1.048 & 5.246 & 5.246 \\
P-value & - & 0.268 & 0.040 & 0.306 & 0.022 & 0.022 \\
\hline
\end{tabular}

significant difference in terms of fully recovered, effective and non-effective between the groups $(\mathrm{P}>0.05)$. The significant effective and total effective rates were lower in group $\mathrm{A}$ than group $\mathrm{B}$, and the difference was statistically significant $(\mathrm{P}<0.05)$ (Table II).
Comparison of changes in arteriosclerosis indexes of lower extremities before and after the treatment between the groups. Before the treatment, there was no difference in terms of the flow of dorsalis pedis artery, superficial femoral artery or posterior tibial artery in the groups. There was no difference 
Table III. Comparison of lower extremity arterial blood flow, ABI and TBI before and after the treatment between the groups $($ mean $\pm \mathrm{SD})$.

\begin{tabular}{|c|c|c|c|c|}
\hline Variables & Group A $(n=94)$ & Group B $(n=112)$ & $\mathrm{t}$ & P-value \\
\hline \multicolumn{5}{|l|}{ Dorsalis pedis artery $\left[\mathrm{m} /\left(\mathrm{s} . \mathrm{cm}^{2}\right)\right]$} \\
\hline Before treatment & $0.51 \pm 0.11$ & $0.52 \pm 0.10$ & 0.683 & 0.495 \\
\hline After the first course of treatment & $0.57 \pm 0.15^{\mathrm{a}}$ & $0.73 \pm 0.21^{\mathrm{a}}$ & 6.180 & $<0.001$ \\
\hline After the second course of treatment & $0.62 \pm 0.20^{\mathrm{a}, \mathrm{b}}$ & $0.80 \pm 0.25^{\mathrm{a}, \mathrm{b}}$ & 5.630 & $<0.001$ \\
\hline $\mathrm{F}$ & 11.470 & 61.190 & & \\
\hline P-value & $<0.001$ & $<0.001$ & & \\
\hline \multicolumn{5}{|l|}{ Superficial femoral artery $\left[\mathrm{m} /\left(\mathrm{s} . \mathrm{cm}^{2}\right)\right]$} \\
\hline Before treatment & $6.12 \pm 1.13$ & $6.46 \pm 1.57$ & 1.753 & 0.081 \\
\hline After the first course of treatment & $6.69 \pm 1.92^{\mathrm{a}}$ & $7.31 \pm 2.01^{\mathrm{a}}$ & 2.251 & 0.026 \\
\hline After the second course of treatment & $7.18 \pm 2.23^{\mathrm{a}, \mathrm{b}}$ & $7.84 \pm 2.27^{\mathrm{a}, \mathrm{b}}$ & 2.095 & 0.037 \\
\hline $\mathrm{F}$ & 7.987 & 13.970 & & \\
\hline P-value & $<0.001$ & $<0.001$ & & \\
\hline \multicolumn{5}{|l|}{ Posterior tibial artery $\left[\mathrm{m} /\left(\mathrm{s} . \mathrm{cm}^{2}\right)\right]$} \\
\hline Before treatment & $6.41 \pm 1.98$ & $6.35 \pm 1.77$ & 0.230 & 0.819 \\
\hline After the first course of treatment & $6.59 \pm 1.79^{a}$ & $7.12 \pm 1.99^{\mathrm{a}}$ & 1.993 & 0.048 \\
\hline After the second course of treatment & $7.03 \pm 2.01^{\mathrm{a}, \mathrm{b}}$ & $7.73 \pm 2.88^{\mathrm{a}, \mathrm{b}}$ & 1.985 & 0.049 \\
\hline $\mathrm{F}$ & 2.570 & 10.440 & & \\
\hline P-value & 0.078 & $<0.001$ & & \\
\hline \multicolumn{5}{|l|}{$\mathrm{ABI}$} \\
\hline Before treatment & $0.58 \pm 0.23$ & $0.59 \pm 0.19$ & 0.342 & 0.733 \\
\hline After the first course of treatment & $0.84 \pm 0.26^{\mathrm{a}}$ & $1.03 \pm 0.32^{\mathrm{a}}$ & 4.617 & $<0.001$ \\
\hline After the second course of treatment & $1.06 \pm 0.25^{\mathrm{a}, \mathrm{b}}$ & $1.25 \pm 0.31^{\mathrm{a}, \mathrm{b}}$ & 4.779 & $<0.001$ \\
\hline $\mathrm{F}$ & 88.97 & 161.7 & & \\
\hline P-value & $<0.001$ & $<0.001$ & & \\
\hline \multicolumn{5}{|l|}{ TBI } \\
\hline Before treatment & $0.32 \pm 0.09$ & $0.33 \pm 0.10$ & 0.748 & 0.455 \\
\hline After the first course of treatment & $0.43 \pm 0.16^{\mathrm{a}}$ & $0.61 \pm 0.24^{\mathrm{a}}$ & 19.540 & $<0.001$ \\
\hline After the second course of treatment & $0.53 \pm 0.13^{\mathrm{a}, \mathrm{b}}$ & $0.77 \pm 0.25^{\mathrm{a}, \mathrm{b}}$ & 8.401 & $<0.001$ \\
\hline $\mathrm{F}$ & 61.49 & 128.1 & & \\
\hline P-value & $<0.001$ & $<0.001$ & & \\
\hline
\end{tabular}

${ }^{\text {aS }}$ Statistical difference $(\mathrm{P}<0.05)$ compared with before the treatment; ${ }^{\mathrm{b}}$ statistical difference compared with the first course of treatment $(\mathrm{P}<0.05)$.

between $\mathrm{ABI}$ and TBI $(\mathrm{P}>0.05)$. After two courses of treatment, compared with the treatment before, the flow of dorsalis pedis artery, superficial femoral artery, posterior tibial artery, ABI and TBI were significantly higher. The increase of group B and group A was statistically significant $(\mathrm{P}<0.05)$ (Table III).

Comparison of PFWD and MVD before and after treatment. There was no significant difference in PFWD and MVD between the groups before the treatment $(\mathrm{P}>0.05)$. The walking distance between the groups was significantly increased after the first course of treatment compared to before the treatment. After the second course of treatment, the walking distance between the groups increased significantly compared with that before the treatment and after the first course of treatment. The walking distance of group B after both the first and second course of treatment was significantly greater than that of group A, and the difference was statistically significant $(\mathrm{P}<0.05)$ (Table IV).

Comparison of adverse reactions of patients between the groups. Group A had 5 cases of digestive tract symptoms $(5.32 \%)$, 15 cases of lethargy hypodynamia $(15.96 \%)$, 3 cases of allergic symptoms $(3.19 \%), 6$ cases of leukopenia $(6.38 \%), 11$ cases of liver dysfunction $(11.70 \%)$ and 9 cases of dizziness and headache (9.57\%). Group B had 5 cases of digestive tract symptoms (4.46\%), 7 cases of lethargy hypodynamia $(6.25 \%), 5$ cases of allergic symptoms (4.46\%), 9 cases of leukopenia (8.04\%), 5 cases of liver dysfunction (4.46\%) and 3 cases of dizziness headache $(2.68 \%)$. There was no significant difference between the groups in digestive tract symptoms, allergic symptoms, leucopenia or liver dysfunction $(\mathrm{P}>0.05)$. There were differences in lethargy hypodynamia, 
Table IV. Comparison of PFWD and MVD before and after treatment (mean \pm SD).

\begin{tabular}{|c|c|c|c|c|c|}
\hline & \multicolumn{3}{|c|}{ PFWD (m) } & \multirow[b]{2}{*}{$\mathrm{F}$} & \multirow[b]{2}{*}{ P-value } \\
\hline & Before treatment & $\begin{array}{c}\text { After the first course } \\
\text { of treatment }\end{array}$ & $\begin{array}{c}\text { After the second course } \\
\text { of treatment }\end{array}$ & & \\
\hline Group A $(n=94)$ & $147.47 \pm 37.46$ & $201.58 \pm 30.46^{\mathrm{a}}$ & $320.48 \pm 44.68^{\mathrm{a}, \mathrm{b}}$ & 510.4 & $\mathrm{P}<0.001$ \\
\hline Group B $(n=112)$ & $145.58 \pm 36.37$ & $290.19 \pm 50.48^{\mathrm{a}}$ & $490.34 \pm 100.37^{\mathrm{a}, \mathrm{b}}$ & 722.2 & $\mathrm{P}<0.001$ \\
\hline $\mathrm{t}$ & 0.367 & 14.890 & 15.190 & & \\
\hline \multirow[t]{3}{*}{ P-value } & 0.714 & $\mathrm{P}<0.001$ & $\mathrm{P}<0.001$ & & \\
\hline & \multicolumn{3}{|c|}{$\operatorname{MVD}(\mathrm{m})$} & \multirow[b]{2}{*}{$\mathrm{F}$} & \multirow[b]{2}{*}{ P-value } \\
\hline & Before treatment & $\begin{array}{c}\text { After the first course } \\
\text { of treatment }\end{array}$ & $\begin{array}{c}\text { After the second course } \\
\text { of treatment }\end{array}$ & & \\
\hline Group A $(n=94)$ & $694.53 \pm 190.23^{a}$ & $822.35 \pm 220.12^{\mathrm{a}}$ & $1,067.45 \pm 300.56^{\mathrm{a}, \mathrm{b}}$ & 57.88 & $\mathrm{P}<0.001$ \\
\hline Group B $(n=112)$ & $689.25 \pm 201.57^{a}$ & $1,098.27 \pm 268.53^{\mathrm{a}}$ & $1,410.45 \pm 320.45^{\mathrm{a}, \mathrm{b}}$ & 204 & $\mathrm{P}<0.001$ \\
\hline $\mathrm{t}$ & 0.192 & 7.965 & 7.871 & & \\
\hline P-value & 0.848 & $\mathrm{P}<0.001$ & $\mathrm{P}<0.001$ & & \\
\hline
\end{tabular}

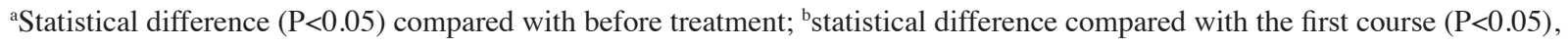

Table V. Comparison of adverse reactions of patients between the groups [n, (\%)].

\begin{tabular}{|c|c|c|c|c|}
\hline & Group A (n=94) & Group B $(n=112)$ & Chi-square test & P-value \\
\hline Digestive tract symptoms & $5 \quad(5.32)$ & $5(4.46)$ & 0.809 & 0.776 \\
\hline Lethargy hypodynamia & $15(15.96)$ & $7(6.25)$ & 5.049 & 0.025 \\
\hline Allergic symptoms & $3(3.19)$ & $5(4.46)$ & 0.222 & 0.638 \\
\hline Leukopenia & $6 \quad(6.38)$ & $9(8.04)$ & 0.207 & 0.649 \\
\hline Liver dysfunction & $11(11.70)$ & $5(4.46)$ & 3.738 & 0.053 \\
\hline Dizziness and headache & $9(9.57)$ & $3(2.68)$ & 4.430 & 0.035 \\
\hline
\end{tabular}

Table VI. Comparison of 5-year survival rates between the groups [n (\%)].

\begin{tabular}{|c|c|c|c|c|c|}
\hline & \multicolumn{5}{|c|}{ Survival time } \\
\hline & 1 year & 2 years & 3 years & 4 years & 5 years \\
\hline Group A (n=94) & $90(95.74)$ & $84(89.36)$ & 75 (79.79) & $63(67.02)$ & $49(52.13)$ \\
\hline Group B (n=112) & $109(97.32)$ & $105(93.75)$ & $98(87.50)$ & $90(80.36)$ & $78(69.64)$ \\
\hline Method of detection & 0.387 & 1.300 & 2.260 & 4.757 & 6.632 \\
\hline P-value & 0.534 & 0.254 & 0.133 & 0.029 & 0.010 \\
\hline
\end{tabular}

dizziness and headache $(\mathrm{P}<0.05)$, which was statistically significant (Table V).

Comparison of 5-year survival rates between the groups. The 1- to 5-year survival rates in group A was 90 cases (95.74\%), 84 cases $(89.36 \%), 75$ cases $(79.79 \%), 63$ cases $(67.02 \%)$, and 49 cases $(52.13 \%)$, respectively. The 1-5-year survival rates in group B was 109 cases (97.32\%), 105 cases (93.75\%),
98 cases (87.50\%), 90 cases $(80.36 \%)$ and 78 cases (69.64\%), respectively. There was no significant difference in 1- to 3-year survival rates between the groups $(\mathrm{P}>0.05)$, the difference in 4-5-year survival rates was statistically significant $(\mathrm{P}<0.05)$ (Table VI). Survival curve diagram shows the 5-year survival of group B treated with cilostazol was more significant than the same group treated with trimetazidine, and the overall survival rate was $\mathrm{P}=0.017$ (Fig. 1). 


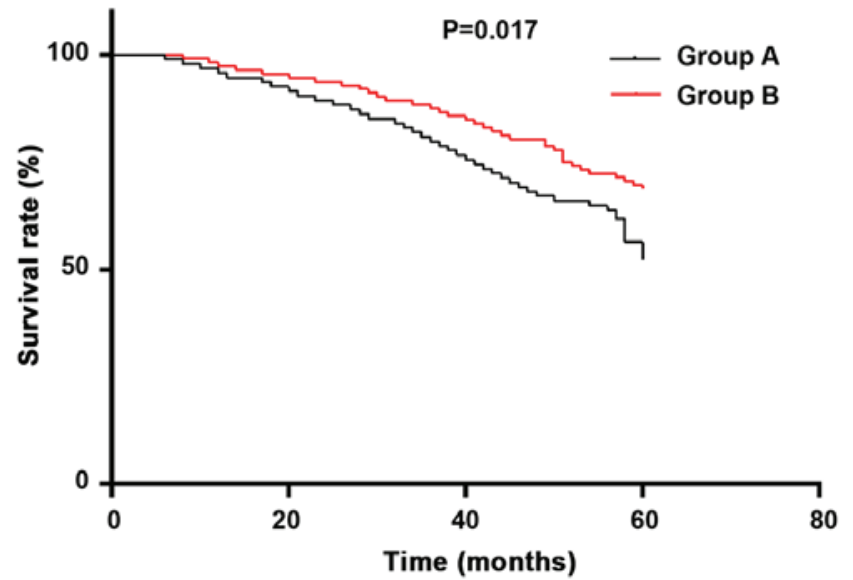

Figure 1. Comparison of 5 -year survival rates between the groups. Survival curve analysis show: The 5-year survival of group B treated with cilostazol was more significant than the group B treated with trimetazidine, and the overall survival rate was higher $(\mathrm{P}=0.017)$

\section{Discussion}

ASO is a degenerative disease that often occurs in the elderly, and the most common symptom is intermittent claudication, and the incidence rate has increased in recent years (12). Its incidence rates, mortality and quality of life are associated with vascular injury (13). It is estimated that there are 202 million individuals worldwide suffering from ASO (14). Impaired perfusion in the femoral artery and arteries are due to stenosis or complete obstruction (occlusion) of the arterial lumen in the distal part of the aorta and/or pelvis. The most important cause of ASO is atherosclerosis (15). If patients do not receive treatment in time, and only start the treatment after the condition becomes severe, then it will cause an unsatisfactory therapeutic effect and may seriously affect the quality of life (16). This reduces the cardiovascular risk of patients, improves the functional performance and quality of life for patients (17).

The current findings showed that the total effective rate of clinical efficacy in patients treated with cilostazol was $90.18 \%$. which was improved compared to that in the patients treated with trimetazidine $(78.72 \%)(\mathrm{P}<0.05)$. It can be concluded that cilostazol is more effective in the treatment of ASO. To further prove this conclusion, we re-checked and analyzed many aspects of ASO indicators, adverse reactions and long-term survival rates. There was no significant difference in lower extremity arterial blood flow, ankle brachial index, toe-brachial index, painless walking distance and maximum walking distance between the groups $(\mathrm{P}>0.05)$. After the first course of treatment, the above indicators have increased in both groups. The difference was statistically significant compared with before the treatment $(\mathrm{P}<0.05)$. After the end of the second course of treatment, the above-mentioned index values in both groups were significantly increased $(\mathrm{P}<0.05)$. However, the improvement of the above indicators in patients treated with cilostazol was better than the trimetazidine group in the first and second course of treatment $(\mathrm{P}<0.05)$. Cilostazol can effectively dilate vascular smooth muscle, promoting blood circulation in patients. The resistance of peripheral arteries is greatly reduced and the fluctuation index is greatly increased. When the blood flow of the surrounding blood vessels is effectively improved, the pain of the lower limbs is reduced, and the maximum walking distance and the painless walking distance of patients are increased. The fluctuation index is greatly increased. When the blood flow of the surrounding blood vessels is effectively improved, and the pain of the lower limbs is reduced, and the maximum walking distance and the painless walking distance of the patient are increased. The main mechanism in addition to being able to expand peripheral blood vessels, inhibits the proliferation of vascular smooth muscles and improve body inflammation while inhibiting thrombosis (18). O'Donnell, et al (19) also stated that cilostole is a safe, effective treatment for sexual well-being. It improves the patients' symptoms and quality of life, and has beneficial effects on arterial compliance through its lipid-lowering properties. Thompson et al (20) pointed out that cilostazol significantly increased patient walking distance and quality of life indicators. Also there are no serious side effects, and this view is consistent with the findings of this study. There was no significant difference between the groups in terms of the number of adverse reactions, the digestive tract symptoms, allergic symptoms, liver function, and leukopenia $(\mathrm{P}>0.05)$. In the trimetazidine group, there were 15 cases of lethargy hypodynamia and 9 cases of dizziness and headache, which were significantly different compared to the cilostazol group ( 7 cases, 3 cases) $(\mathrm{P}<0.05)$. Patients with cilostazol had fewer symptoms such as lethargy hypodynamia, dizziness and headaches, and these symptoms are related to the role of drugs in dilating cerebral blood vessels. It is suggested that cilostazol is more obvious than the tromethazine in the function of dilating blood vessels. Due to platelets having an important effect in the development of atherosclerosis in patients, cilostazol inhibits phosphodiesterase activity, decreases cAMP degradation, and increases cAMP levels in platelets and cells (21). Therefore, it acts as an anti-platelet aggregation and dilating blood vessels to prevent thrombotic vascular occlusion. Syrkin et al (22) reported that trimetazidine has a certain anti-ischemic effect in the treatment of intermittent claudication and cardiac diseases. It has a beneficial effect on extending the intermittent claudication distance; however, the side effects cannot be ignored and further research is required. Through the observation of the long-term survival rates of patients between the groups, the 5 -year survival rate of patients taking cilostazol was $69.64 \%$, whereas the 5-year survival rate of the trimetazidine group was $52.13 \%$, which was much lower than the cilostazol group, and there was a significant difference between the groups $(\mathrm{P}<0.05)$. Based on the above results, the significant high survival rate further confirmed that cilostazol has a better drug efficacy. Also the only two drug treatments approved by the US Food and Drug Administration for use in the United States, include pentoxifylline and cilostazol (23). In 2016, the American College of Cardiology/American Heart Association regarding the management of patients with lower extremity arterial disease (24) indicated that cilostazol may be used as a drug of choice for the treatment of lower extremity peripheral arterial disease. Cilostazol has been shown to be effective in improving intermittent claudication 
in patients with PAD in several clinical trials (25), showing that the efficacy of cilostazol is worthy of recognition.

There was no difference between the experimental group and the control group in terms of sex, age, and lifestyle and other general clinical baseline data. This improved the authenticity and reliability of our experiment. In addition to the efficacy of trimetazidine and cilostazol in the treatment of ASO, the disease index and other adverse reactions were observed statistically. The 5-year survival rate between the groups of patients were recorded in detail and the data were proved by the results, which reflects the rigor of the experiment. The purpose of our experimental research is to extend the research results obtained to a larger population and make a valuable contribution. However, given the limited medical resources in The Central Hospital of Wuhan, the number of selected cases is insufficient. This may result in a lack of wide range of representations and the research conclusion obtained in the laboratory cannot be widely applied.

In conclusion, cilostazol has a good clinical effect in the treatment of ASO, with few adverse reactions and high long-term survival rate, and it is worthy of being promoted in clinical practice.

\section{Acknowledgements}

Not applicable.

\section{Funding}

No funding was received.

\section{Availability of data and materials}

The datasets used and/or analyzed during the present study are available from the corresponding author on reasonable request.

\section{Authors' contributions}

MH drafted the manuscript. $\mathrm{MH}$ and DW were responsible for analysis of the observation indexes. $\mathrm{MH}$ and $\mathrm{TH}$ analyzed and interpreted the patient data regarding the arteriosclerosis obliterans in lower extremity. All authors read and approved the final manuscript.

\section{Ethics approval and consent to participate}

The study was approved by the Ethics Committee of The Central Hospital of Wuhan, Tongji Medical College, Huazhong University of Science and Technology (Wuhan, China). Patients who participated in this research had complete clinical data. Signed informed consents were obtained from the patients or guardians.

\section{Patient consent for publication}

Not applicable.

\section{Competing interests}

The authors declare that they have no competing interests.

\section{References}

1. Kim TD, Rea D, Schwarz M, Grille P, Nicolini FE, Rosti G, Levato L, Giles FJ, Dombret H, Mirault T, et al: Peripheral artery occlusive disease in chronic phase chronic myeloid leukemia patients treated with nilotinib or imatinib. Leukemia 27: 1316-1321, 2013.

2. He XM, Zheng YQ, Liu SZ, Liu Y, He YZ and Zhou XY: Altered plasma microRNAs as novel biomarkers for arteriosclerosis obliterans. J Atheroscler Thromb 23: 196-206, 2016.

3. Suzuki J, Shimamura M, Suda H, Wakayama K, Kumagai H, Ikeda Y, Akazawa H, Isobe M, Komuro I and Morishita R: Current therapies and investigational drugs for peripheral arterial disease. Hypertens Res 39: 183-191, 2016.

4. Zhang J, He S, Wang X and Wang D: Effect of trimetazidine on heart rate variability in elderly patients with acute coronary syndrome. Pak J Med Sci 32: 75-78, 2016.

5. Chang J, Im GJ, Chae SW, Lee SH, Kwon SY, Jung HH, Chung AY, Park HC and Choi J: Protective role of trimetazidine against neomycin-induced hair cell damage in zebrafish. Clin Exp Otorhinolaryngol 6: 219-225, 2013.

6. Atilgan D,Parlaktas BS,Uluocak N,ErdemirF,MarkocF, SaylanO and Erkorkmaz U: The effects of trimetazidine and sildenafil on bilateral cavernosal nerve injury induced oxidative damage and cavernosal fibrosis in rats. ScientificWorldJournal 2014: 970363 , 2014.

7. Aksoy F, Dogan R, Ozturan O, Eren SB, Veyseller B Pektas A and Hüseyinbas Ö: Protective effect of trimetazidine on amikacin-induced ototoxicity in rats. Int J Pediatr Otorhinolaryngol 78: 663-669, 2014

8. Stadnik M, Handzlik-Orlik G, Sarnecki K, Krysiak R and Okopień B: Clinical aspects of the use of trimetazidine in the prevention and treatment of myocardial diseases. Przegl Lek 70: 730-734, 2013 (In Polish).

9. Rondina MT and Weyrich AS: Targeting phosphodiesterases in anti-platelet therapy. Handb Exp Pharmacol 210: 225-238, 2012.

10. Kohda N, Tani T, Nakayama S, Adachi T, Marukawa K, Ito R, Ishida K, Matsumoto Y and Kimura Y: Effect of cilostazol, a phosphodiesterase III inhibitor, on experimental thrombosis in the porcine carotid artery. Thromb Res 96: 261-268, 1999.

11. Sakamoto T, Ohashi W, Tomita K, Hattori K, Matsuda N and Hattori Y: Anti-inflammatory properties of cilostazol: Its interruption of DNA binding activity of NF- $\kappa \mathrm{B}$ from the Toll-like receptor signaling pathways. Int Immunopharmacol 62: 120-131, 2018.

12. Criqui $\mathrm{MH}$ and Aboyans V: Epidemiology of peripheral artery disease. Circ Res 116: 1509-1526, 2015.

13. Mozaffarian D, Benjamin EJ, Go AS, Arnett DK, Blaha MJ, Cushman M, Das SR, de Ferranti S, Després JP, Fullerton HJ, et al; Writing Group Members; American Heart Association Statistics Committee; Stroke Statistics Subcommittee: Executive Summary: Heart disease and stroke statistics - 2016 update: A report from the American Heart Association. Circulation 133: 447-454, 2016.

14. Fowkes FG, Rudan D, Rudan I, Aboyans V, Denenberg JO, McDermott MM, Norman PE, Sampson UK, Williams LJ, Mensah GA, et al: Comparison of global estimates of prevalence and risk factors for peripheral artery disease in 2000 and 2010: A systematic review and analysis. Lancet 382: 1329-1340, 2013.

15. Lawall H, Huppert P, Espinola-Klein C and Rümenapf G: The diagnosis and treatment of peripheral arterial vascular disease. Dtsch Arztebl Int 113: 729-736, 2016.

16. Chong PF, Garratt AM, Golledge J, Greenhalgh RM and Davies AH: The intermittent claudication questionnaire: A patient-assessed condition-specific health outcome measure. J Vasc Surg 36: 764-771, discussion 863-864, 2002.

17. Kurklinsky AK and Levy M: Effect of ramipril on walking times and quality of life among patients with peripheral artery disease and intermittent claudication: a randomized controlled trial. Journal of the American Medical Association 2013; 309: 453-460. Vasc Med 18: 234-236, 2013.

18. Chao TH, Chen IC, Lee CH, Chen JY, Tsai WC, Li YH, Tseng SY, Tsai LM and Tseng WK: Cilostazol enhances mobilization of circulating endothelial progenitor cells and improves endothelium-dependent function in patients at high risk of cardiovascular disease. Angiology 67: 638-646, 2016. 
19. O'Donnell ME, Badger SA, Sharif MA, Young IS, Lee B and Soong CV: The vascular and biochemical effects of cilostazol in patients with peripheral arterial disease. J Vasc Surg 49: 1226-1234, 2009.

20. Thompson PD, Zimet R, Forbes WP and Zhang P: Meta-analysis of results from eight randomized, placebo-controlled trials on the effect of cilostazol on patients with intermittent claudication. Am J Cardiol 90: 1314-1319, 2002

21. Asal NJ and Wojciak KA: Effect of cilostazol in treating diabetes-associated microvascular complications. Endocrine 56 : 240-244, 2017.

22. Syrkin AL, Artiukhina EG, Kanorskiı̌ SG and Chuntyzheva MM: Antiischemic efficacy of trimetazidine in patients with intermittent claudication and effort angina. Kardiologiia 43: 49-52, 2003 (In Russian).

23. Roset PN: Systematic review of the efficacy of cilostazol, naftidrofuryl oxalate and pentoxifylline for the treatment of intermittent claudication (Br J Surg 2012; 99: 1630-1638). Br J Surg 100: 1838, 2013.
24. No authors listed: Correction to: 2016 AHA/ACC Guideline on the Management of Patients With Lower Extremity Peripheral Artery Disease: A Report of the American College of Cardiology/American Heart Association Task Force on Clinical Practice Guidelines. Circulation 135: e791-e792, 2017.

25. Pearce L, Ghosh J, Counsell A and Serracino-Inglott F: Cilostazol and peripheral arterial disease. Expert Opin Pharmacother 9: 2683-2690, 2008.

This work is licensed under a Creative Commons Attribution-NonCommercial-NoDerivatives 4.0 International (CC BY-NC-ND 4.0) License. 